\title{
A Fiber Ring Laser Sensor with a Side Polished Evanescent Enhanced Fiber for Highly Sensitive Temperature Measurement
}

\author{
Weihao Lin ${ }^{1,2} \mathbb{D}$, Yibin Liu ${ }^{1}$, Liyang Shao ${ }^{1, * \mathbb{C}}$ and Mang I. Vai ${ }^{2, *}$ \\ 1 Department of Electrical and Electronic Engineering, Southern University of Science and Technology, \\ Shenzhen 518055, China; 11510630@mail.sustech.edu.cn (W.L.); 11853004@mail.sustech.edu.cn (Y.L.) \\ 2 Department of Electrical and Computer Engineering, Faculty of Science and Technology, University of Macau, \\ Macau 999078, China \\ * Correspondence: shaoly@sustech.edu.cn (L.S.); fstmiv@um.edu.mo (M.I.V.); Tel.: +86-0755-8801-8136 (L.S.)
}

\section{check for}

updates

Citation: Lin, W.; Liu, Y.; Shao, L.; Vai, M.I. A Fiber Ring Laser Sensor with a Side Polished Evanescent Enhanced Fiber for Highly Sensitive Temperature Measurement. Micromachines 2021, 12, 586. https:// doi.org/10.3390/mi12050586

Academic Editors: Qammer Hussain Abbasi, Syed Aziz Shah, Naeem Ramzan and Muhammad Ali Imran

Received: 21 April 2021

Accepted: 17 May 2021

Published: 20 May 2021

Publisher's Note: MDPI stays neutral with regard to jurisdictional claims in published maps and institutional affiliations.

Copyright: (c) 2021 by the authors. Licensee MDPI, Basel, Switzerland. This article is an open access article distributed under the terms and conditions of the Creative Commons Attribution (CC BY) license (https:// creativecommons.org/licenses/by/ $4.0 /)$.

\begin{abstract}
We demonstrate a highly sensitive and practical fiber-based temperature sensor system The sensor is constructed based on a fiber ring laser (FRL) as well as a side-polished fiber filled with isopropanol. The laser cavity of the sensing part fiber is polished by the wheel fiber polishing system with residual thickness (RT) is selected to detect the temperature in the FRL. Thanks to the high thermo-optic coefficient of isopropanol, the sensitivity of the proposed temperature sensor could be effectively improved by filling isopropanol in the cost-less side polished single mode fiber. Refractive index (RI) of isopropanol changes with the surrounding temperature variation allowing high-sensitivity temperature sensing. Experimental results demonstrate that the side polished fiber can efficiently excite high-order cladding modes which enhance the modular interference increase the interaction between the evanescent wave and the isopropanol. Besides, the results show that the sensitivity can be as high as $2 \mathrm{~nm} /{ }^{\circ} \mathrm{C}$ in the temperature range of $25-35^{\circ} \mathrm{C}$.
\end{abstract}

Keywords: fiber ring laser; temperature sensor; side-polished fiber; isopropanol

\section{Introduction}

In recent years, optical fiber sensors have attracted increased interest in aerospace [1], industrial manufacturing [2], medical [3] and other fields, since they offer the advantages of small volume, simple structure, high sensitivity, electromagnetic interference resistance and anti-corrosion properties [4]. In addition, dual-parameter sensors or multi-parameter sensors have been developed and many studies have focused on solving the cross-sensitivity issue [5]. Among them, fiber temperature sensors have been widely explored due to the acceleration of industrial modernization and the rapid development of the information electronics industry. Different kinds of optic fiber temperature sensors have been proposed, i.e., fiber Bragg gratings [6], Mach-Zehnder interferometers (MZIs) [7] and Fabry-Perot interferometers (FPIs) [8]. However, the fabrication and application of these sensing structure enhance the deterioration, resulting in low accuracy of the peak wavelength determination. Wang proposed a response time for an optical microfiber temperature sensor based on the microfiber modal interferometer with sensitivity of $-406 \mathrm{pm} /{ }^{\circ} \mathrm{C}$ [9]. Lei et al., demonstrated an optical fiber temperature sensor based on a dual-loop optoelectronic oscillator (OEO) with the Vernier effect by using slightly different lengths of single mode fiber [10]. Besides, there are various optical fiber structures designed for temperature measurement [11-15].

Recently, side polished types of fiber sensors have attracted much attention [16-18]. These free devices from the need for additional fiber filters. Pei et al. used a full vector finite element method to design a D-shaped double clad fiber temperature sensor based on surface plasmon resonance (SPR) with sensitivity of $-3.635 \mathrm{~nm} /{ }^{\circ} \mathrm{C}[19]$. However, a gold film is needed to coat the fiber, which greatly increases the cost. Jian et al. proposed a novel fiber optic magnetic field sensor based on D-shaped fiber optic modal interferometer 
filled with a magnetic fluid [20]. The magnetic field sensitivity is $99.68 \mathrm{pm} / \mathrm{Oe}$ and the temperature sensitivity is $-77.49 \mathrm{pm} /{ }^{\circ} \mathrm{C}$. The performance of these sensors in terms of temperature is typically limited, the further improvement is desired. In order to meet the requirements of high signal-to-noise ratio and narrow 3-dB bandwidth, optical fiber ring laser sensor systems [21-23] have been widely used in recent years. Benefitting from a side-polished optical fiber structure, in 2010 a temperature sensor based on a side-polished fiber (SPF) coupled to a tapered multimode overlay waveguide (MMOW) was proposed by Prerana [24]. Chen et al. designed a novel fiber structure in 2018, in which a coreless sidepolished fiber that is wrapped in polydimethylsiloxane [25], whereby a high temperature sensitivity of $-0.4409 \mathrm{~nm} /{ }^{\circ} \mathrm{C}$ is achieved. Wang el al, demonstrated a surface plasmon resonance (SPR) of a side-polished single mode fiber for temperature sensing thanks to the high thermo-optic and thermal expansion coefficient of the adhesive [26]. In addition, many works describing optical fiber temperature sensors have been reported [19,27-30].

To address the aforementioned challenges and difficulties, we have designed and fabricated a new sensing system to measure the temperature of the ambient environment by using a side polished evanescent enhanced fiber structure filled with isopropanol in a fiber ring laser system. When the grinding depth is $70.9 \mu \mathrm{m}$ and $75.5 \mu \mathrm{m}$, the temperature sensitivity is measured to be $-1.601 \mathrm{~nm} /{ }^{\circ} \mathrm{C}$ and $-1.921 \mathrm{~nm} /{ }^{\circ} \mathrm{C}$, respectively. The theoretical basis and experimental results are discussed in detail. The OSNR of $50 \mathrm{~dB}$ and narrow bandwidth of $0.15 \mathrm{~nm}$ have been achieved. Furthermore, the stability of power fluctuation and wavelength shift are also tested and analyzed.

\section{Working Principle}

The experimental setup of the proposed temperature sensor is illustrated in Figure 1. A wavelength division multiplexer (WDM) is used to interconnect the $976 \mathrm{~nm}$ pump laser source into a $1.6 \mathrm{~m}$ long erbium-doped fiber (EDF) as the gain medium. Afterwards it is connected to an isolator (ISO) to prevent backscattering light. A polarization controller (PC) is inserted in the temperature sensor to regulate the polarization state, the $1 \%$ port of the output coupler is used to export light from the FRL cavity for analyzing the temperature change.

Figure 2 illustrates the schematic diagram of the proposed side polished fiber filled with isopropanol configuration, and the inset shows the cross-sectional view of the side polished fiber employed in the experiment. When the incident light transmitting through the single mode fiber with a fundamental mode reach the side-polished region, leading mismatch between core diameter. Hence, the incident light from the incident fiber is split into two parts by the first polishing point, denoted by $I_{\text {core }}$ and $I_{\text {cavity }}$. The interference happens when the two beams recombine at the core of the fiber, and the resultant interference light intensity can be mathematically described by the following equation:

$$
I_{O U T}(\lambda)=I_{c l}+I_{c o}+2 \sqrt{I_{c l} I_{c o}} \cos \phi
$$

where $I_{\mathcal{~} o}$ and $I_{c l}$ delegate the light intensities of beams transmitting through the resid ual core and the side-opened fiber, respectively. 


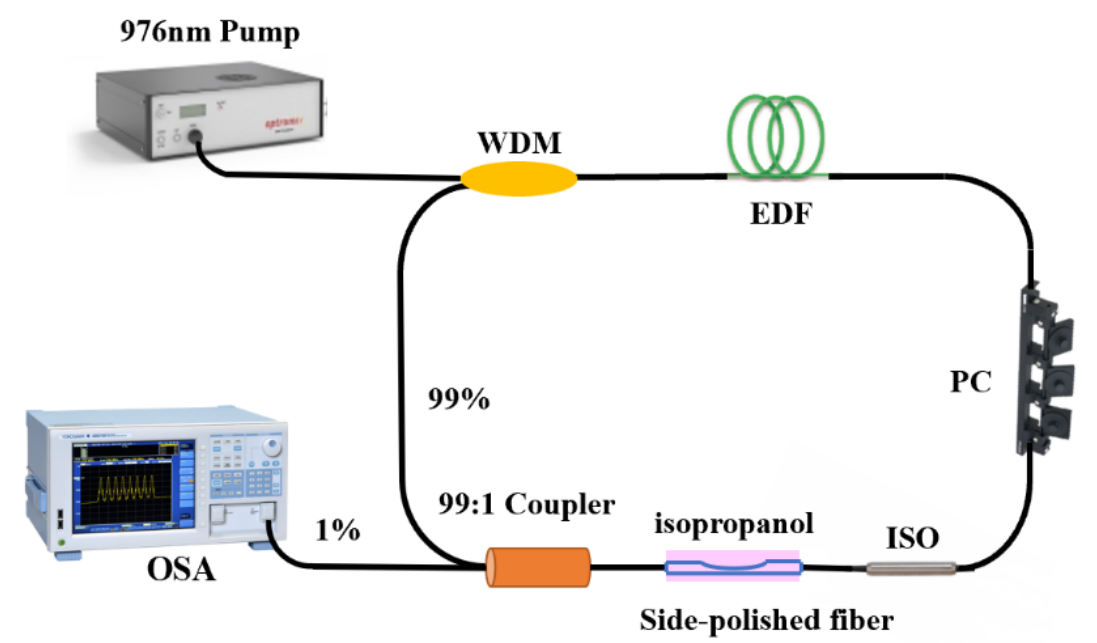

Figure 1. Experiment setup of the temperature FRL sensing system.

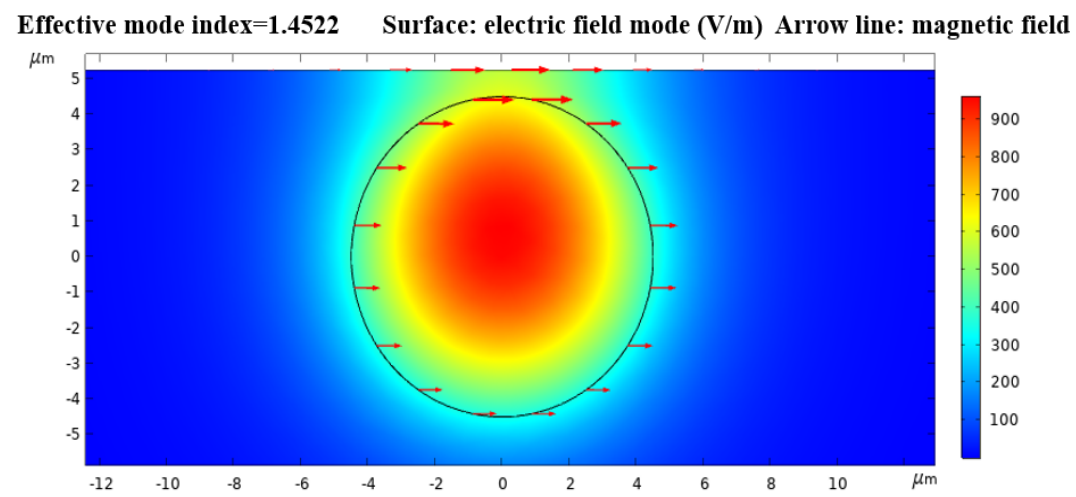

Figure 2. The electric and magnetic transmission field simulation in COMSOL.

The evanescent wave in cladding mode can be enhanced effectively by polishing the fiber side. In light of the optical transmission process, the refractive index of the cladding modes and core mode rely on the temperature $(\mathrm{T})$ for the thermal-optical coefficient of fiber. The equation could be further simplified as [31]:

$$
\Phi=\frac{2 \pi}{\lambda}\left[n_{e f f}^{c o}(\lambda, T)-n_{e f f}^{c l, m}\left(\lambda, T, R I_{e x t}\right)\right] L=\frac{2 \pi \Delta n_{e f f}^{m}\left(\lambda, T, R I_{e x t}\right) L}{\lambda}
$$

where $n_{\text {eff }}^{c o}(\lambda, T)$ is the refractive index of the core mode with respect to the temperature change and $n_{\text {eff }}^{c l, m}\left(\lambda, T, R I_{\text {ext }}\right)(m=1,2,3 \ldots)$ is the refractive index of the $m$-th-cladding modes with respect to the temperature change, $\Delta n_{e f f}^{m}\left(\lambda, T, R I_{e x t}\right) L$ is the dissimilarity between the cladding modes and core mode, $L$ represents the length of side-polished fiber and $\lambda$ is the center wavelength of input pump source which is $976 \mathrm{~nm}$.

The fringe visibility of the interferogram is calculated as follows:

$$
V=\frac{2 \sqrt{I_{\text {core }} I_{\text {cavity }}}}{I_{\text {core }}+I_{\text {cavity }}}
$$

Equation (3) shows that the visibility of fringes of interference pattern is mainly determined by the intensity of the core mode and the cavity mode, that is, the smaller the intensity difference between the core mode and the air mode in the grinding and polishing area, the higher the visibility of the fringes of the interference pattern. In the structure of optical fiber based on measurement and polishing, the output region is used as the input coupler of mode excitation, which means that the lateral offset plays an important role in 
the performance of MZI. In addition, the different grinding depth loss and transmission loss of the core mode and cavity mode also affect the visibility of the fringes. Therefore, we use the COMSOL method to study the waveguide electric field transmission characteristics at $1550 \mathrm{~nm}$ wavelength, and the results are shown in Figure 2. It can be seen that some energy transmitted outside the fiber core.

At the end of the introduced fiber, most of the light intensity is concentrated in the SMF core and a small amount of light intensity is distributed in the SMF cladding. If the transverse offset is introduced at the first splice point, the core mode and cavity mode will be excited simultaneously when the incident light is coupled to the polished fiber. The larger the lateral offset is, the more energy is coupled into the cavity mode. This makes it possible to obtain MZI with excellent performance according to Equation (3), which represents a very clear interference spectrum with high signal-to-noise ratio and fringe visibility.

Equation (2) shows that the phase difference between the core mode and the cavity mode strongly depends on their effective RI difference and the length of the interference region. If 1 is a constant, the temperature sensitivity of MZI can be expressed by Equation (4) [18,32]:

$$
\frac{d \lambda}{d T}=\frac{\lambda}{n_{\text {eff }}^{\text {core }}(T)-n_{e f f}^{\text {cavity }}(T)}\left(\frac{d n_{e f f}^{\text {core }}(T)}{d T}-\frac{d n_{e f f}^{\text {cavity }}(T)}{d T}\right)
$$

where $\frac{d n_{e f f}^{\text {core }}(T)}{d T}$ and $\frac{d n_{e f f}^{\text {core }}(T)}{d T}$ are the thermo-optic coefficients of the RI of fiber core and isopropanol, respectively. The core of the single mode fiber's thermo-optic coefficient $d$ $8.6 \times 10^{-6} /{ }^{\circ} \mathrm{C}$. While isopropanol with high thermo-optic coefficient of $\sim-4.5 \times 10^{-4} /{ }^{\circ} \mathrm{C}$ is infiltrated into the side polished fiber, the core mode and the isopropanol mode vary quickly and differently when the temperature changes. Besides, since the refractive index value of isopropanol changes with the temperature [21], the effective RI difference between the core mode and the cavity mode will increase with the increment of temperature.

Two different depth of the side-polished fiber were fabricated. The single mode fiber was fabricated by a wheel-based side polishing technique, as shown in Figure 3. where a supercontinuum light source (ASE-C-N, Hoyatek, Shenzhen, China) and an optical spectrum analyzer (OSA, AQ6370D, Yokogawa, Japan) are included. The two ends of the fiber were fixed in the pulley and a $2 \mathrm{~g}$ weight is used to straighten the fiber and reduce any vibrations. As shown in Figure 4, the side polished area length is $8 \mathrm{~mm}$ and the remnants fiber thickness of the fiber section is about half of the total fiber size, The variations of residual thickness are measured by the microscopy, since the air-cavity is closer to the core, the interaction with core mode and surrounding RI is more sensitivity to temperature, besides, to protect the fiber from being destroyed waists of $75.5 \mu \mathrm{m}$ and $70.9 \mu \mathrm{m}$ are selected for temperature sensing as shown in Figure 5.

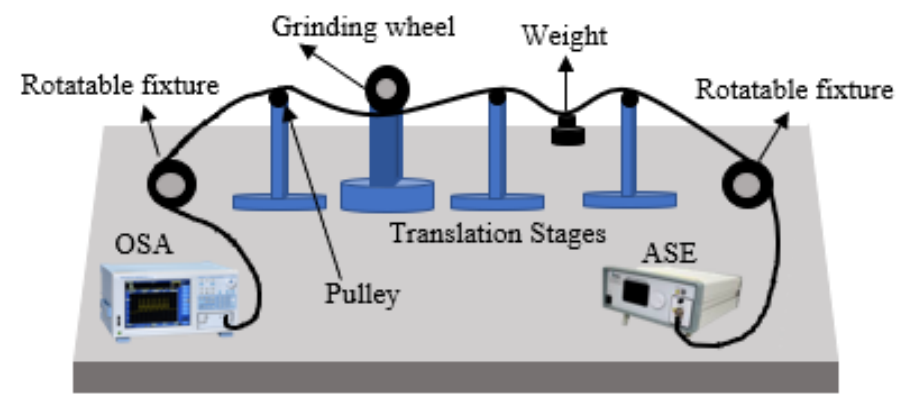

Figure 3. Fiber side-polished system diagram. 


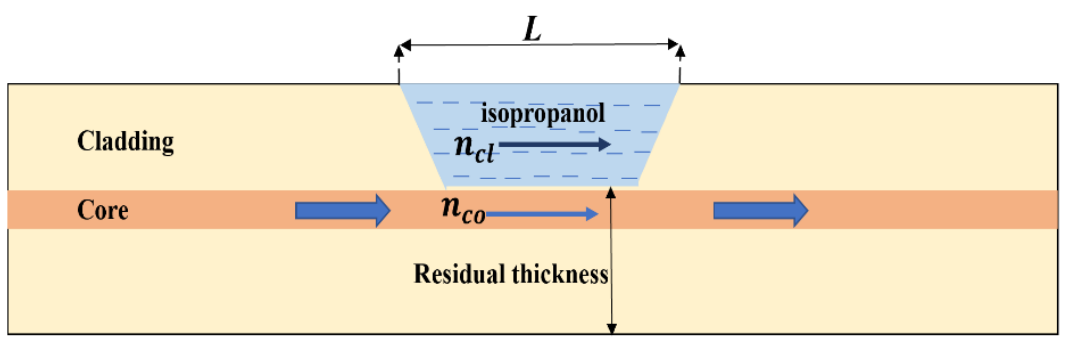

Figure 4. Schematic diagram for the proposed side-polished fiber filled with isopropanol.
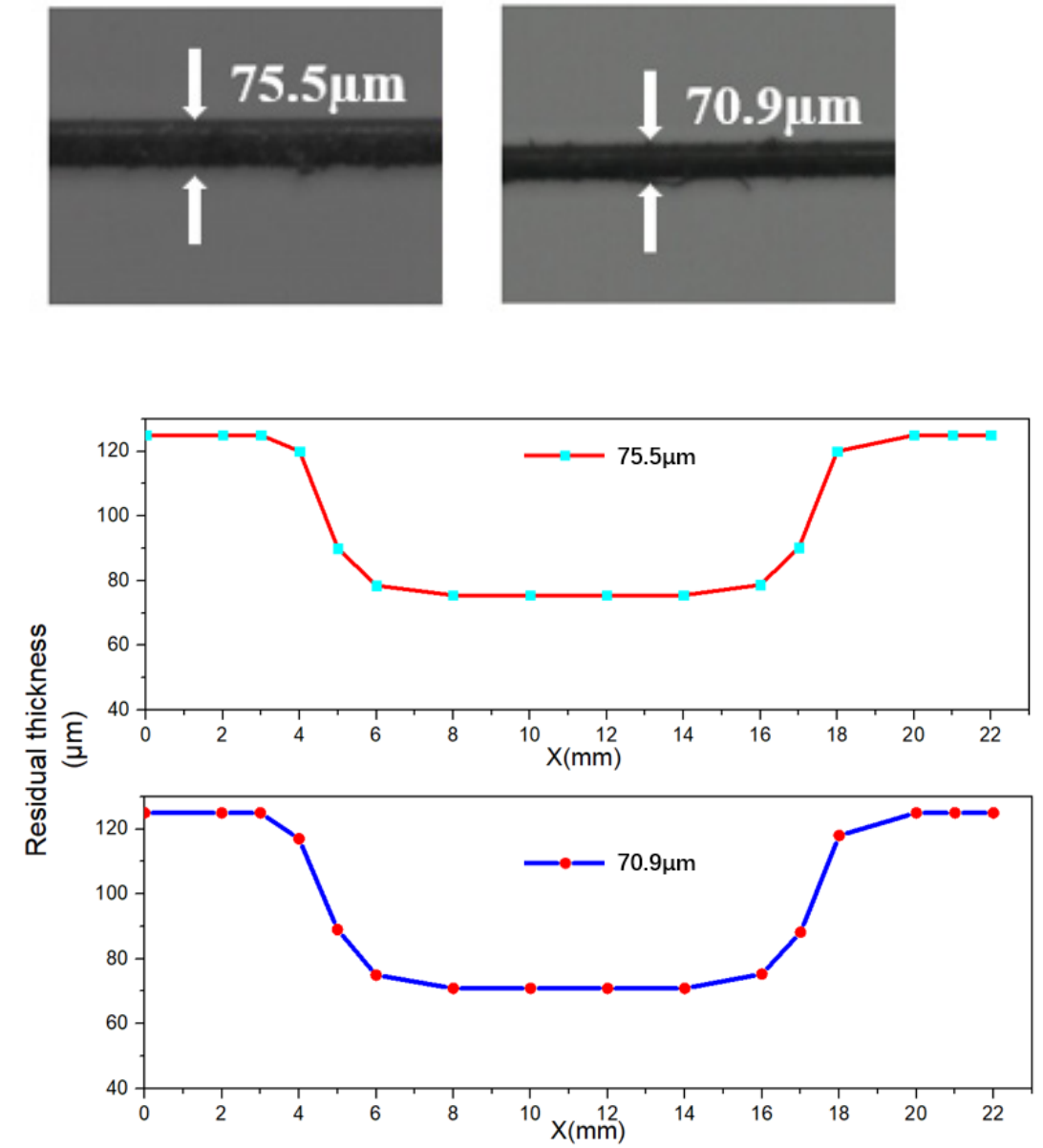

Figure 5. Side view microscopic images of the RT of Side-polished fibers. The RTs were measured as $75.5 \mu \mathrm{m}$ and $70.9 \mu \mathrm{m}$, respectively and Variations of residual thicknesses for the two fabricated side-polished fibers.

\section{Experimental Results and Discussion}

Figure 6a shows the output spectrum of the FRL sensing system, whose emission wavelength is $\sim 1550 \mathrm{~nm}$ with a threshold pump power of about $400 \mathrm{~mW}$. The emission wavelength of FRL depends on minimum spectral transmission loss, which is mainly determined by the filtering characteristics of the side-polished fiber. Figure 6a shows the output spectrum on the core-off set structure. The SNR of the structure is more than $60 \mathrm{~dB}$, and the $3 \mathrm{~dB}$ bandwidth is less than $0.06 \mathrm{~nm}$.

In order to verify the sensing performance of the side-polished fiber optic sensor based on FRL system. The initial response to the surrounding RI was tested, as shown in Figure $6 \mathrm{a}, \mathrm{b}$. The wavelength shifts to a short wavelength with refractive index changed from 1.3339 to 1.3865 . As shown in Figure $6 \mathrm{~b}$, the $R^{2}$ value is 0.978 which indicates that the 
system has a good linearity to the surrounding environment change and the sensitivity is 46.903 nm/RIU.
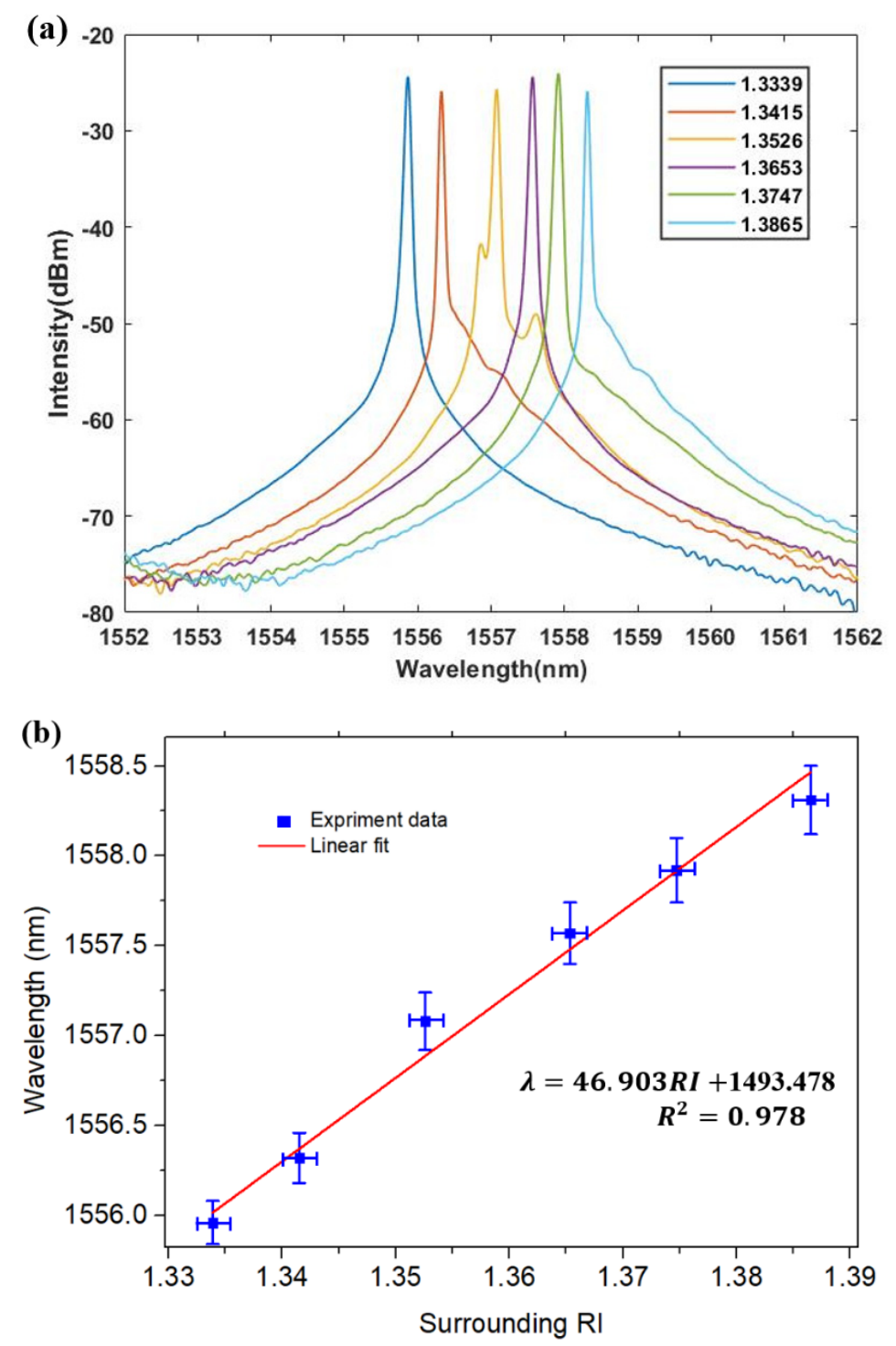

Figure 6. (a) Measured output spectra of the RI from 1.3339 to 1.3865 for $75.5 \mu \mathrm{m}$ side-polished fiber; (b) Measured Linear relationship of the RI from 1.3339 to 1.3865 for $75.5 \mu \mathrm{m}$ side-polished fiber.

With the increase of temperature $t$ the transmission spectrum of the side polished fiber in the FRL system shifts accordingly. When the temperature is changed from $25^{\circ} \mathrm{C}$ to $31^{\circ} \mathrm{C}$, the spectral response to the different temperatures is shown in Figure $7 \mathrm{a}, \mathrm{b}$. Note that the transmission spectrum undergoes a blueshift with the increase of temperature. As shown in Figure $7 \mathrm{~b}$, the temperature sensitivity is $-1.60 \mathrm{~nm} /{ }^{\circ} \mathrm{C}$. When the diameter of the fiber is $75.5 \mu \mathrm{m}$, the relationship between the emission wavelength and the temperature can be fitted linearly $\left(R^{2}=0.998\right)$. 
(a)
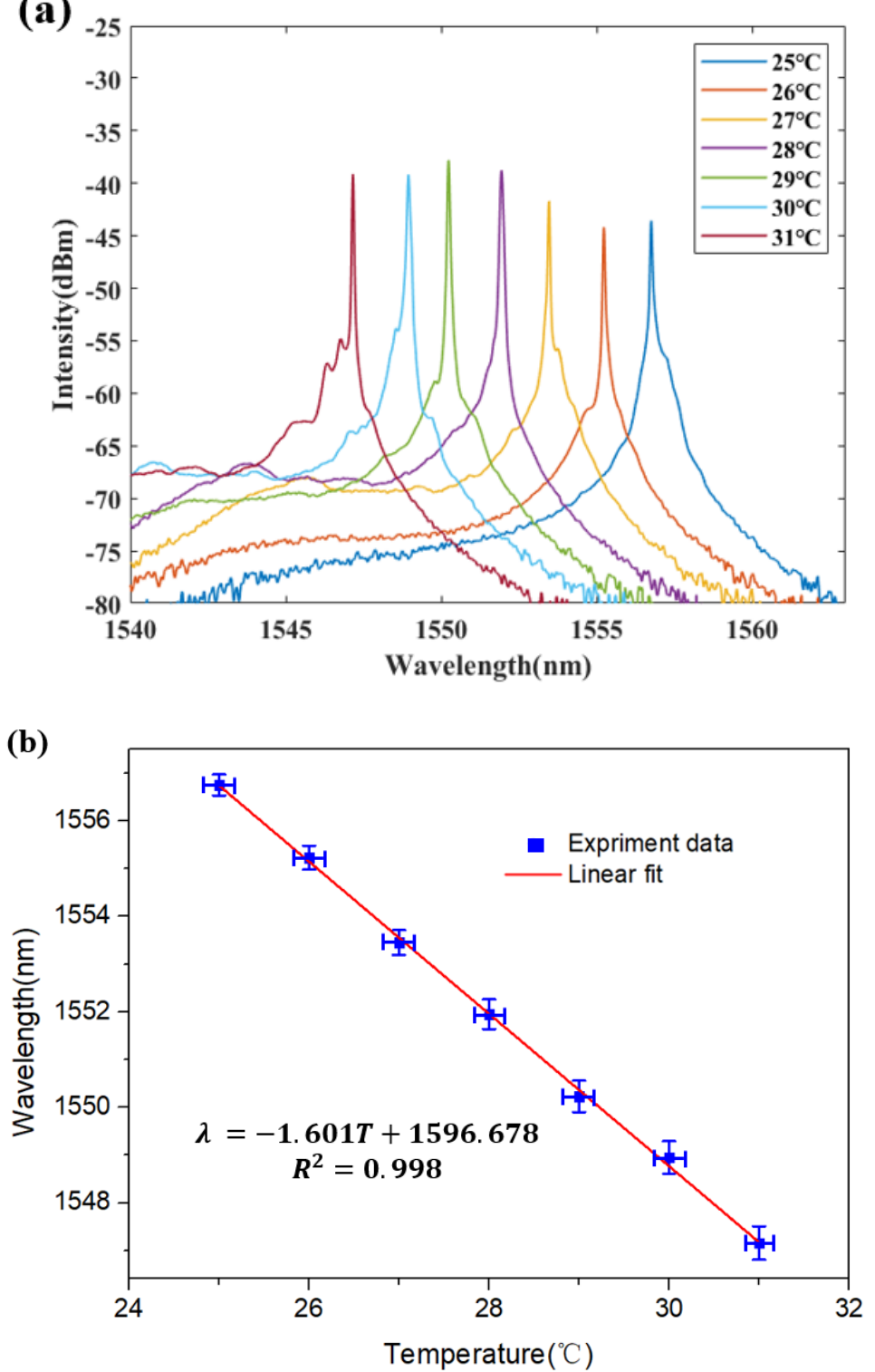

Figure 7. (a) Measured output spectra of the $75.5 \mu \mathrm{m}$ side-polished fiber temperature sensor at various temperatures; (b) Linear relationship of wavelength spacing for $75.5 \mu \mathrm{m}$ side polished fiber.

The temperature change of the FRL system with polished fiber diameter of $70.9 \mu \mathrm{m}$ and the spectral change over the $25-35^{\circ} \mathrm{C}$ range are shown in Figure $8 \mathrm{a}, \mathrm{b}$. As shown in Figure $8 \mathrm{~b}$ the emission wavelength shifts from $1565.21 \mathrm{~nm}$ to $1545.62 \mathrm{~nm}$, corresponding to a temperature sensitivity of $-1.96 \mathrm{~nm} /{ }^{\circ} \mathrm{C}\left(R^{2}=0.999\right)$.

For the FRL-based sensing system, the stability of the output spectrum is very important. In order to measure the stability of the sensor system, the output power was recorded every $10 \mathrm{~min}$ at room temperature for $220 \mathrm{~min}$. The results are shown in Figure 9. for $70.9 \mu \mathrm{m}$ side-polished fiber. It is observed that the sensor shows an excellent stability for the temperature response. The variation of wavelength value and power is less than $0.03 \mathrm{~nm}$ and $1.2 \mathrm{~dB}$.

The performance between the proposed isopropanol-sealed side-polished fiber in FRL and other temperature FRL sensing system in previous works is compared in Table 1. Here, our proposed temperature sensor shows higher sensitivity compared with other temperature sensors. 
(a)
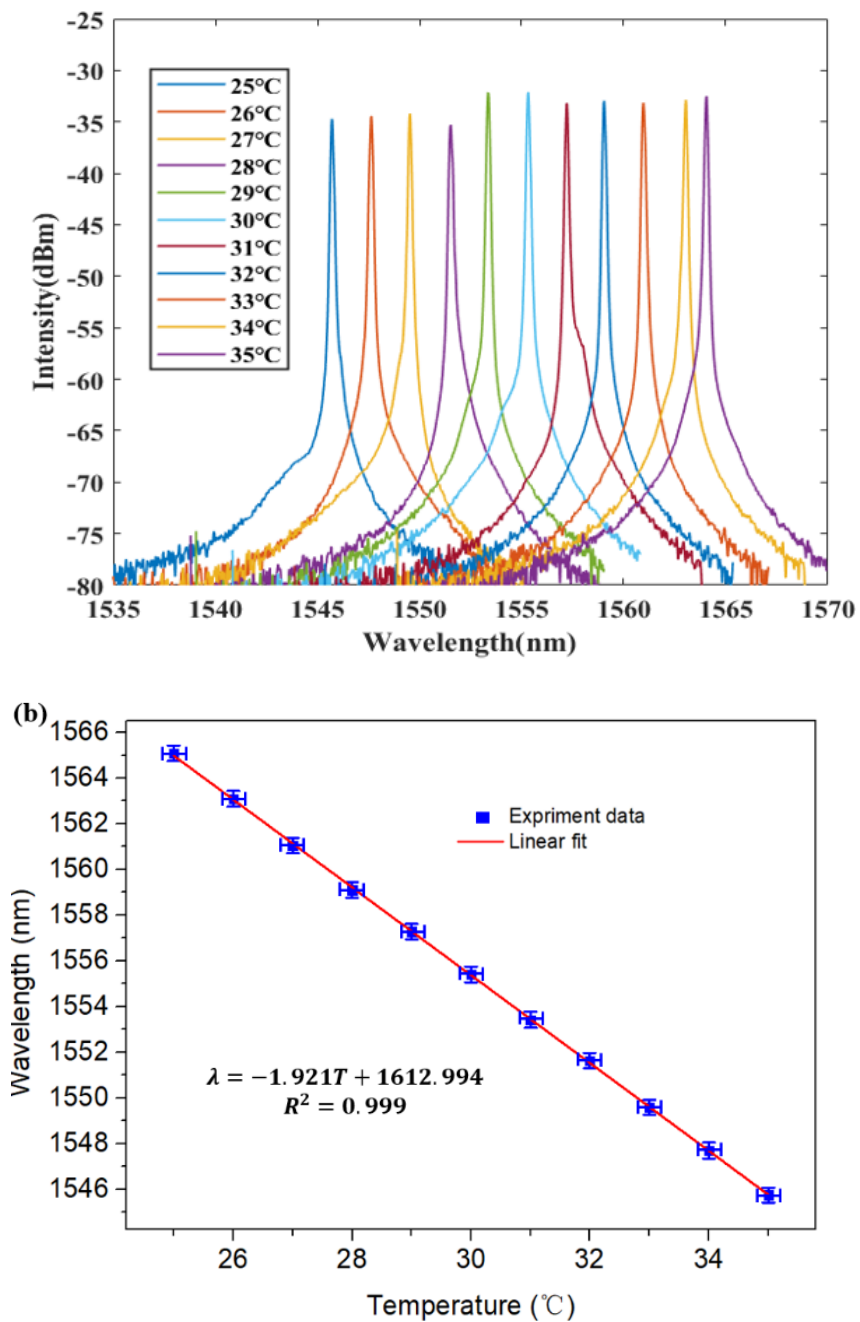

Figure 8. (a) Measured output spectra of the $70.9 \mu \mathrm{m}$ side-polished fiber temperature sensor at various temperature. (b) Linear relationship of wavelength spacing for $70.9 \mu \mathrm{m}$ side-polished fiber.

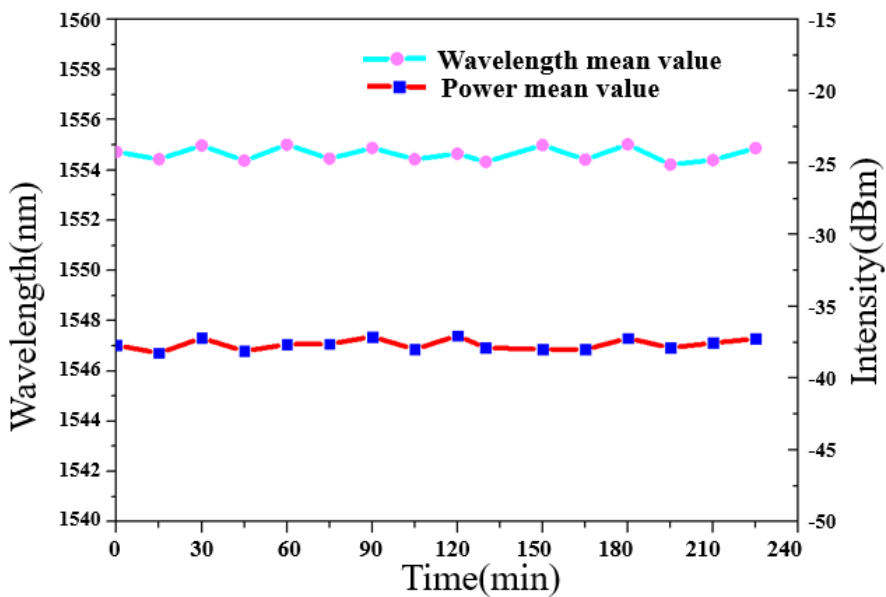

Figure 9. Test for time stability of wavelength shift and power fluctuation. 
Table 1. Comparison with other FRL sensing structures.

\begin{tabular}{ccc}
\hline Strucutres & Sensitivity & Refs. \\
\hline Three-core fiber + LPFG & $47 \mathrm{pm} /{ }^{\circ} \mathrm{C}$ & {$[33]$} \\
Dual-tapered SCF & $53.2 \mathrm{pm} /{ }^{\circ} \mathrm{C}$ & {$[34]$} \\
All-solid photonic bandgap fiber & $50.9 \mathrm{pm} /{ }^{\circ} \mathrm{C}$ & {$[35]$} \\
Polyimide FBG in fiber ring laser & $9.6 \mathrm{pm} /{ }^{\circ} \mathrm{C}$ & {$[36]$} \\
Current work & $-1.92 \mathrm{~nm} /{ }^{\circ} \mathrm{C}$ & - \\
\hline
\end{tabular}

\section{Conclusions}

In summary, a compact side-polished fiber temperature sensor filled with isopropanol is developed in FRL. The sensing mechanism of the side-polished fiber and its sensing performance are analyzed. The comparative output wavelength of the FRL has an excellent linearity with the ambient temperature in a range of $25-35^{\circ} \mathrm{C}$. The temperature sensitivity of $70.9 \mu \mathrm{m}$ side-polished fiber is obtained as $\sim-2 \mathrm{~nm} /{ }^{\circ} \mathrm{C}$. The sensor has a narrow $3-\mathrm{dB}$ bandwidth of less than $0.06 \mathrm{~nm}$ and high SNR of about $60 \mathrm{~dB}$. Moreover, due to the highly narrow bandwidth, the proposed sensor scheme is very suitable for remote monitoring of ambient temperatures. This present side-polished fiber filled with isopropanol in FRL can be a competitive candidate for temperature sensing applications due to its high sensitivity, cost-effective configuration, simple fabrication process and strong mechanical ability.

Author Contributions: Conceptualization, W.L. and Y.L.; methodology, W.L.; software, Y.L.; validation, L.S., W.L. and Y.L.; formal analysis, Y.L.; investigation, M.I.V.; resources, W.L.; data curation, W.L.; writing—original draft preparation, W.L.; writing—review and editing, Y.L.; visualization, L.S.; supervision, L.S.; project administration, M.I.V.; funding acquisition, M.I.V. All authors have read and agreed to the published version of the manuscript.

Funding: This work was supported by the startup fund from Southern University of Science and Technology and Shenzhen government.

Conflicts of Interest: The authors declare no conflict of interest.

\section{References}

1. Zhang, W.; Webb, D.J.; Lao, L.Y.; Hammond, D.; Carpenter, M.; Williams, C. Water content detection in aviation fuel by using PMMA based optical fiber grating. Sens. Actuators B Chem. 2019, 282, 774-779. [CrossRef]

2. Wang, G.Y.; Lu, Y.; Duan, L.C.; Yao, J.Q. A Refractive Index Sensor Based on PCF With Ultra-Wide Detection Range. IEEE J. Sel. Top. Quant. 2021, 27, 1-8. [CrossRef]

3. Chen, C.; Wang, J. Optical biosensors: An exhaustive and comprehensive review. Analyst 2020, 145, 1605-1628. [CrossRef] [PubMed]

4. Floris, I.; Adam, J.M.; Calderon, P.A.; Sales, S. Fiber Optic Shape Sensors: A comprehensive review. Opt. Lasers Eng. 2021, 139, 106508. [CrossRef]

5. Li, W.C.; Yuan, Y.G.; Yang, J.; Yuan, L.B. Review of Optical Fiber Sensor Network Technology Based on White Light Interferometry. Photonic Sens. 2021, 11, 31-44. [CrossRef]

6. Liu, Y.C.; Mataira, R.; Badcock, R.; Jiang, Z.N.; Fang, J. Application of Epoxy-Bonded FBG Temperature Sensors for HighTemperature Superconductor-Coated Conductor Quench Detection. IEEE Tran. Appl. Supercon. 2021, 31, 1-8. [CrossRef]

7. Yang, W.; Li, C.; Wang, M.; Yu, X.; Fan, J.; Xiong, Y.; Yang, Y.; Li, L. The Polydimethylsiloxane Coated Fiber Optic for All Fiber Temperature Sensing Based on the Multithin-Multifiber Structure. IEEE Sens. J. 2021, 21, 51-56. [CrossRef]

8. Lee, B.H.; Kim, Y.H.; Park, K.S.; Eom, J.B.; Kim, M.J.; Rho, B.S.; Choi, H.Y. Interferometric fiber optic sensors. Senors 2012, 12, 2467-2486. [CrossRef]

9. Wen, J.-H.; Wang, J.; Yang, L.; Hou, Y.-F.; Huo, D.-H.; Cai, E.-L.; Xiao, Y.-X.; Wang, S.-S. Response Time of Microfiber Temperature Sensor in Liquid Environment. IEEE Sens. J. 2020, 20, 6400-6407. [CrossRef]

10. Cheng, Y.; Wang, Y.; Song, Z.; Lei, J. High-sensitivity optical fiber temperature sensor based on a dual-loop optoelectronic oscillator with the Vernier effect. Opt. Express 2020, 28, 35264-35271. [CrossRef]

11. Ren, X.; Gao, J.; Shi, H.; Huang, L.; Zhao, S.; Xu, S. A highly sensitive all-fiber temperature sensor based on the enhanced green upconversion luminescence in Lu2MoO6:Er3+/Yb3+ phosphors by co-doping Li+ ions. Optik 2021, 227, 166084. [CrossRef]

12. Nan, T.; Liu, B.; Wu, Y.; Wang, J.; Mao, Y.; Zhao, L.; Sun, T.; Wang, J. Optical fiber temperature sensor with insensitive refractive index and strain based on phase demodulation. Microw. Opt. Technol. Lett. 2020, 62, 3733-3738. [CrossRef] 
13. Xu, Y.; Chen, X.; Zhu, Y. High Sensitive Temperature Sensor Using a Liquid-core Optical Fiber with Small Refractive Index Difference Between Core and Cladding Materials. Sensors 2008, 8, 1872-1878. [CrossRef]

14. Xu, B.; Li, J.; Li, Y.; Xie, J.; Dong, X. Ultrasensitive Temperature Sensor Based on Refractive Index Liquid-Sealed Thin-Core Fiber Modal Interferometers. IEEE Sens. J. 2014, 14, 1179-1184. [CrossRef]

15. Ma, J.; Wu, S.; Cheng, H.; Yang, X.; Wang, S.; Lu, P. Sensitivity-enhanced temperature sensor based on encapsulated S-taper fiber Modal interferometer. Opt. Laser Technol. 2021, 139, 106933. [CrossRef]

16. Wang, Y.J.; Li, S.G.; Wang, M.Y.; Yu, P.T. Refractive index sensing and filtering characteristics of side-polished and gold-coated photonic crystal fiber with a offset core. Opt. Laser Technol. 2021, 136, 106759. [CrossRef]

17. Caucheteur, C.; Guo, T.; Albert, J. Review of plasmonic fiber optic biochemical sensors: Improving the limit of detection. Anal Bioanal. Chem. 2015, 407, 3883-3897. [CrossRef] [PubMed]

18. Yang, X.; Bandyopadhyay, S.; Shao, L.-Y.; Xiao, D.; Gu, G.; Song, Z. Side-Polished DBR Fiber Laser with Enhanced Sensitivity for Axial Force and Refractive Index Measurement. IEEE Photonics J. 2019, 11, 1-10. [CrossRef]

19. Weng, S.; Pei, L.; Wang, J.; Ning, T.; Li, J. High sensitivity D-shaped hole fiber temperature sensor based on surface plasmon resonance with liquid filling. Photonics Res. 2017, 5, 103-107. [CrossRef]

20. Dong, Y.; Wu, B.; Wang, M.; Xiao, H.; Xiao, S.; Sun, C.; Li, H.; Jian, S. Magnetic field and temperature sensor based on D-shaped fiber modal interferometer and magnetic fluid. Opt. Laser Technol. 2018, 107, 169-173. [CrossRef]

21. Liu, X.; Zhang, X.; Yang, J.; Du, X. Dual-ring dual-wavelength fiber laser sensor for simultaneous measurement of refractive index and ambient temperature with improved discrimination and detection limit. Appl. Opt. 2019, 58, 7582-7587. [CrossRef]

22. Han, M.; Liu, T.; Hu, L.; Zhang, Q. Intensity-demodulated fiber-ring laser sensor system for acoustic emission detection. Opt. Express 2013, 21, 29269-29276. [CrossRef] [PubMed]

23. Shao, L.Y.; Liang, J.W.; Zhang, X.P.; Pan, W.; Yan, L.S. High-Resolution Refractive Index Sensing With Dual-Wavelength Fiber Laser. IEEE Sens. J. 2016, 16, 8463-8467. [CrossRef]

24. Prerana, P.; Varshney, R.K.; Pal, B.P.; Nagaraju, B. High Sensitive Fiber Optic Temperature Sensor Based on a Side-polished Single-mode Fiber Coupled to a Tapered Multimode Overlay Waveguide. J. Opt. Soc. Korea 2010, 14, 337-341. [CrossRef]

25. He, C.; Fang, J.; Zhang, Y.; Yang, Y.; Yu, J.; Zhang, J.; Guan, H.; Qiu, W.; Wu, P.; Dong, J.; et al. High performance all-fiber temperature sensor based on coreless side-polished fiber wrapped with polydimethylsiloxane. Opt. Express 2018, 26, 9686-9699. [CrossRef] [PubMed]

26. Liu, S.; Cao, S.; Zhang, Z.; Wang, Y.; Liao, C.; Wang, Y. Temperature Sensor Based on Side-Polished Fiber SPR Device Coated with Polymer. Sensors 2019, 19, 4063. [CrossRef]

27. An, G.; Li, S.; Qin, W.; Zhang, W.; Fan, Z.; Bao, Y. High-Sensitivity Refractive Index Sensor Based on D-Shaped Photonic Crystal Fiber with Rectangular Lattice and Nanoscale Gold Film. Plasmonics 2014, 9, 1355-1360. [CrossRef]

28. Chen, A.; Yu, Z.; Dai, B.; Li, Y. Highly Sensitive Detection of Refractive Index and Temperature Based on Liquid-Filled D-Shape PCF. IEEE Photonics Technol. Lett. 2021, 33, 529-532. [CrossRef]

29. Dong, Y.; Xiao, S.; Xiao, H.; Liu, J.; Sun, C.; Jian, S. An Optical Liquid-Level Sensor Based on D-Shape Fiber Modal Interferometer. IEEE Photonics Technol. Lett. 2017, 29, 1067-1070. [CrossRef]

30. Tan, R.X.; Ho, D.; Tse, C.H.; Tan, Y.C.; Yoo, S.W.; Tjin, S.C.; Ibsen, M. Birefringent Bragg Grating in C-Shaped Optical Fiber as a Temperature-Insensitive Refractometer. Sensors 2018, 18, 3285. [CrossRef]

31. Dong, Y.; Xiao, S.Y.; Wu, B.L.; Xiao, H.; Jian, S.S. Refractive Index and Temperature Sensor Based on D-Shaped Fiber Combined With a Fiber Bragg Grating. IEEE Sens. J. 2019, 19, 1362-1367. [CrossRef]

32. Sun, M.; Jin, Y.; Dong, X. All-Fiber Mach-Zehnder Interferometer for Liquid Level Measurement. IEEE Sens. J. 2015, 15, 3984-3988. [CrossRef]

33. Geng, T.; He, J.; Yang, W.L.; Chen, X.D.; An, M.W.; Sun, C.T.; Jin, X.R.; Yuan, L.B. Modal Interferometer Using Three-Core Fiber for Simultaneous Measurement Strain and Temperature. IEEE Photonics J. 2016, 8, 1-8. [CrossRef]

34. Madry, M.; Alwis, L.; Binetti, L.; Pajewski, L.; Beres-Pawlik, E. Simultaneous Measurement of Temperature and Relative Humidity Using a Dual-Wavelength Erbium-Doped Fiber Ring Laser Sensor. IEEE Sens. J. 2019, 19, 9215-9220. [CrossRef]

35. Wu, Z.; Zhang, H.; Shum, P.P.; Shao, X.; Huang, T.; Seow, Y.M.; Liu, Y.G.; Wei, H.; Wang, Z. Supermode Bragg grating combined Mach-Zehnder interferometer for temperature-strain discrimination. Opt. Express 2015, 23, 33001-33007. [CrossRef]

36. Gan, L.; Wang, R.X.; Liu, D.M.; Duan, L.; Liu, S.; Fu, S.N.A.; Li, B.R.; Feng, Z.H.; Wei, H.F.; Tong, W.J.; et al. Spatial-Division Multiplexed Mach-Zehnder Interferometers in Heterogeneous Multicore Fiber for Multiparameter Measurement. IEEE Photonics J. 2016, 8, 1-8. [CrossRef] 